\title{
New approach to analyzing physics problems: A Taxonomy of Introductory Physics Problems
}

\author{
Raluca E. Teodorescu, Cornelius Bennhold, ${ }^{*}$ Gerald Feldman, and Larry Medsker ${ }^{\dagger}$ \\ Department of Physics, George Washington University, Washington, D.C., 20052, USA
}

(Received 25 June 2011; published 10 January 2013)

\begin{abstract}
This paper describes research on a classification of physics problems in the context of introductory physics courses. This classification, called the Taxonomy of Introductory Physics Problems (TIPP), relates physics problems to the cognitive processes required to solve them. TIPP was created in order to design educational objectives, to develop assessments that can evaluate individual component processes of the physics problem-solving process, and to guide curriculum design in introductory physics courses, specifically within the context of a "thinking-skills" curriculum. Moreover, TIPP enables future physics education researchers to investigate to what extent the cognitive processes presented in various taxonomies of educational objectives are exercised during physics problem solving and what relationship might exist between such processes. We describe the taxonomy, give examples of classifications of physics problems, and discuss the validity and reliability of this tool.
\end{abstract}

DOI: 10.1103/PhysRevSTPER.9.010103

PACS numbers: 01.40. $-\mathrm{d}, 01.50 .-\mathrm{i}$

\section{INTRODUCTION}

Physics education research (PER) has made great progress in recent years in adopting important findings from expert-novice [1-3] and cognitive science [4] research. These findings imply that asking students to solve high-level thinking problems can help them become more expertlike problem solvers. To achieve this goal, physics problem developers have made efforts to create physics problems that move the novices towards a more expertlike status [5-9]. However, to successfully use such problems in the curriculum, one needs to understand the relationship between the problems themselves and the thinking processes and the knowledge that they involve, because the instruction is ultimately determined by the targeted type of knowledge and thinking processes. Such a relationship is not easy to establish due to the complexity and the dynamic character of the problem-solving process [10-13]. Therefore, it is imperative that its limitations and its range of applicability are carefully explained. By problem solving we mean "cognitive processing directed at achieving a goal when no solution method is obvious to the problem solver" [14]. By taxonomy we mean "an orderly classification of items according to their presumed natural relationship" [15].

We have examined relevant taxonomies of educational objectives and adopted one for the purpose of classifying physics problems. Research shows that a given problem's

\footnotetext{
*Deceased.

${ }^{\dagger}$ Also at: Departments of Computer Science and Physics and Astronomy, Siena College, Loudonville, NY 12211, USA.

Published by the American Physical Society under the terms of the Creative Commons Attribution 3.0 License. Further distribution of this work must maintain attribution to the author(s) and the published article's title, journal citation, and DOI.
}

classification is not solely an inherent characteristic of the problem. Problems that appear to be simple to physicists are often not seen that way by students [16]. Our taxonomy of physics problems is developed under the assumption that students have not been exposed to the particular problem (or similar ones) and they have internalized only very basic relevant knowledge. This is because a student who solves the same problem many times engages in different cognitive processes than a student who sees the problem for the first time. The physics problems that we consider in this project are any pen-and-paper tasks that can range from standard textbook problems to research-based sequences of activities.

Our taxonomy is an adaptation of a taxonomy of educational objectives to one for physics problem solving. Taxonomies of educational objectives are informed by national reports, cognitive science, and educational psychology research. They have high degrees of generality and are not subject specific. As more discoveries are made in those domains, they are updated and revised. We present evidence that the thinking processes and the knowledge included in such taxonomies can be applicable to physics problem solving, but we believe that additional research is needed for a more complete understanding of the processes that take place during physics problem solving.

\section{DESIGN OF THE TAXONOMY OF INTRODUCTORY PHYSICS PROBLEMS}

As collections of research-based physics problems have become more numerous and diverse, PER groups have undertaken attempts to classify these problems. This has been done explicitly $[17,18]$ by establishing categories of existing physics problems or implicitly [7] by labeling the problems created by different groups. The uniqueness of our Taxonomy of Introductory Physics Problems (TIPP) 
derives from the fact that it is based on a taxonomy of educational objectives and on research on physics problem solving. Our taxonomy was developed to address the following questions:

- Can physics problems be categorized according to cognitive processes and knowledge domains?

- Is there any relationship between physics problems, knowledge domains, and cognitive processes?

- Are there relevant cognitive processes that are not activated by existing physics problems?

In developing TIPP, we applied the following procedure:

(1) We considered cognitive processes and knowledge domains that PER researchers $[5,19,20]$ identified as relevant for physics problem solving.

(2) We searched among taxonomies of educational objectives [21-26] and found one that presents the problem-solving process consistent with PER findings.

(3) We developed an algorithm that uses this taxonomy to classify the physics problems according to the cognitive processes and knowledge they involve.

(4) We constructed TIPP which is a database containing text-based and research-based physics problems that explains their relationships to cognitive processes and knowledge.

(5) We assessed the validity and reliability of TIPP.

\section{A. Choosing an appropriate taxonomy of educational objectives}

Taxonomies of educational objectives are tools, mainly used in K-12 education, to guide instructors in planning and assessing their curricular activities. Among existing taxonomies [21-26], we searched to find one suitable for our purpose.

The criteria we used to select the taxonomy were

(1) addresses problem solving,

(2) involves both knowledge domains and cognitive processes that have been identified by PER as relevant for physics problem solving,

(3) makes a clear distinction between the cognitive processes and the knowledge involved in problem solving.

With the above criteria in mind, we have analyzed several popular taxonomies of educational objectives [21-26] searching for one suitable for physics problem classifications. Bloom [21] combines knowledge domains with cognitive processes and so does not satisfy criterion (3). Anderson et al. [22] did not include problem solving in their taxonomy; thus, that taxonomy does not satisfy criterion (1). Haladyna [23] and Hannah and Michaelis [24] do not address the knowledge domains, and therefore fail to satisfy criterion (3). Biggs and Collis [25] treat the problem-solving process from the perspective of Piagetian phases: preoperational, early concrete, middle concrete, concrete generalization, and formal operation.
They describe only some aspects of mathematical problem solving and do not discuss knowledge domains. Therefore, their taxonomy fails to satisfy criteria (2) and (3). The new Taxonomy of Educational Objectives (NTEO) [26] developed by Marzano and Kendall contains problem solving in the list of cognitive processes; thus, it satisfies criterion (1). Also, it involves cognitive processes identified by PER as relevant for physics problem solving; thus, it satisfies criterion (2). Later in the paper we will describe how the problem-solving knowledge and cognitive processes emphasized by PER can be mapped into this taxonomy. NTEO makes a clear distinction between the knowledge and the cognitive processes and therefore it satisfies criterion (3). As NTEO satisfies all of the above criteria, we have therefore chosen NTEO as the basis for TIPP.

\section{B. The New Taxonomy of Educational Objectives}

Briefly, NTEO is a two-dimensional framework having three systems of thinking as one dimension and three domains of knowledge as the other dimension. The actions of the three systems (self, metacognitive, and cognitive) upon the three knowledge domains (information, mental procedures, and psychomotor procedures) are driven by the levels of the student's consciousness of processing. They are hierarchically ordered in the following six levels:

- Level 6: Self-system

- Level 5: Metacognitive system

- Level 4: Knowledge utilization (cognitive system)

- Level 3: Analysis (cognitive system)

- Level 2: Comprehension (cognitive system)

- Level 1: Retrieval (cognitive system)

The highest level (6) denotes the so-called self-system that contains a network of interrelated beliefs, attitudes, and expectations that are involved in making judgments as to whether to engage in a new task. It is at this level that the motivation for accomplishing the goal is determined. If the decision is made to engage in a new task, the metacognitive system (level 5) is activated. At this level, goals relevant to the new task would be defined and strategies would be developed for reaching those goals. Finally, the cognitive system (levels 1-4) is responsible for the effective processing of the knowledge.

For the purpose of this project, we will restrict ourselves to the four cognitive system levels, and we will not include the metacognitive aspects in our taxonomy, although it may be extended to include levels 5 and 6 at a later stage. We do, however, want to acknowledge that we believe that levels 5 and 6 are important for physics problem solving. It is known that what students believe about physics as a science and what they expect from their physics courses can determine their attitude and motivation towards the process of learning physics [27-30]. However, we think that it is more appropriate to focus initially on the cognitive aspects of problem solving and then to extend the 
taxonomy to metacognitive aspects after establishing a solid framework.

In NTEO, the self, metacognitive, and cognitive systems operate upon the other dimension of the taxonomy, namely, the type of knowledge. Clearly, the success of accomplishing a certain task is highly dependent on the amount and the quality of the necessary knowledge. According to NTEO, the knowledge that is specific to any subject area can be organized into three general categories or knowledge domains: information, mental procedures, and psychomotor procedures. Each domain is further subdivided as shown in Table I.

Mental procedures are different in both form and function from information; while the latter specifies the "what" of a particular task, the former refers to the "how" of accomplishing that task.

The final knowledge domain of psychomotor procedures, obviously essential in areas such as neurosurgery

TABLE I. Summary of the knowledge domains according to NTEO [26].

\begin{tabular}{ll}
\hline \hline Knowledge domains & \\
\hline Information & Vocabulary terms (basic informational knowledge) \\
& Facts (informational content that contains many vocabulary terms) \\
& Time sequences (description of events that has a temporal component) \\
Generalizations (statements for which examples can be provided) & Principles (specific types of generalizations that deal with relationships) \\
& Single rules (mental procedures involving one step or a few simple steps) \\
Mental procedures & Algorithms (a set of specific steps performed in a certain order) \\
& Tactics (a set of steps not necessarily performed in a certain order) \\
& Macroprocedures (complex procedures that involve many subprocedures) \\
Psychomotor procedures & Not applicable to pen-and-paper problem solving \\
\hline
\end{tabular}

TABLE II. A summary of Marzano's new Taxonomy of Educational Objectives [26]. All of the categories listed below apply to the two knowledge domains of information and mental procedures. (The only exception is sublevel (1b)—executing-which applies only to mental procedures and not to information as the information cannot be executed.)

Level 1: Retrieval

Level 2: Comprehension

Level 3: Analysis

Level 4: Knowledge utilization a) Recalling and recognizing_-producing or recognizing basic physics knowledge related to the problem (but not necessarily understanding the structure of the knowledge).

b) Executing - performing a procedure or task needed to solve the problem without significant error (but not necessarily understanding how and why the procedure works).

a) Integrating-identifying the basic structure of the physics knowledge and separating the critical from the noncritical characteristics of the problem.

b) Symbolizing - constructing an accurate symbolic image of the information or mental procedure needed to solve the physics problem.

a) Matching-identifying similarities or differences and relationships between the physics problem components.

b) Classifying -identifying superordinate and subordinate categories into which physics knowledge related to a problem can be organized.

c) Analyzing errors-making reasonable assumptions and estimates related to the physics knowledge involved in the problem.

d) Generalizing-constructing new generalizations or principles from available physics knowledge.

e) Specifying - generating new applications or logical consequences from available physics knowledge.

a) Decision making — selecting between two or more alternatives.

b) Overcoming obstacles (problem solving)—accomplishing a goal or task for which obstacles or limiting conditions exist.

c) Experimenting — generating and testing hypotheses for the purpose of understanding phenomena, using rules of evidence that adhere to statistical hypothesis testing.

d) Investigating - generating and testing hypotheses about past, present and future events, using well-constructed and logical arguments as evidence. 
or piloting an airplane, is not relevant to solving pen-andpaper introductory physics problems and is therefore not considered in this project.

Table II summarizes NTEO-our outline for creating the taxonomy of introductory physics problems. Level $4 d$ in NTEO is called problem solving, and we renamed it overcoming obstacles for reasons presented in the next section.

In summary, Fig. 1 shows an adaptation of the model of behavior implied by NTEO. In this model, when a student is presented with a new problem, he or she uses previous beliefs and expectations (contained in the selfsystem) to decide to engage or not in solving it. If a positive decision has been reached, the metacognitive system sets learning goals and strategies to achieve them. Once goals are set, the cognitive system processes the relevant knowledge (information and mental procedures). The interaction between the three systems, and between each one of them and the knowledge, is dynamic and continual. In the current form, TIPP focuses only on the interaction between the cognitive system and the knowledge.
We consider the grounding of TIPP on a taxonomy that is in agreement with PER findings as an essential part of the TIPP design. Previous work on physics problem solving pointed out various aspects related to the cognitive processes and the knowledge involved in it. Ross [19] explained that the knowledge targeted in physics problem solving can be of two types: declarative and procedural. The relevant knowledge domains in NTEO also involve declarative knowledge (or information) and procedural knowledge (or mental procedures).

Beatty et al. [5] discussed several cognitive processes "that expert physicists possess and students should develop." Those processes are listed in Table III. In the same table we show how they can be mapped into NTEO. It should be noted that this mapping is based on our interpretation of the meaning given by authors to the action verbs. For instance, we mapped "discuss" into analyzing errors because the authors explain that students discuss in small groups and "they argue their opinions and intuitions," which suggests that they check the reasonableness of their opinions and intuitions. This is consistent with the definition of analyzing errors in NTEO. If the authors did

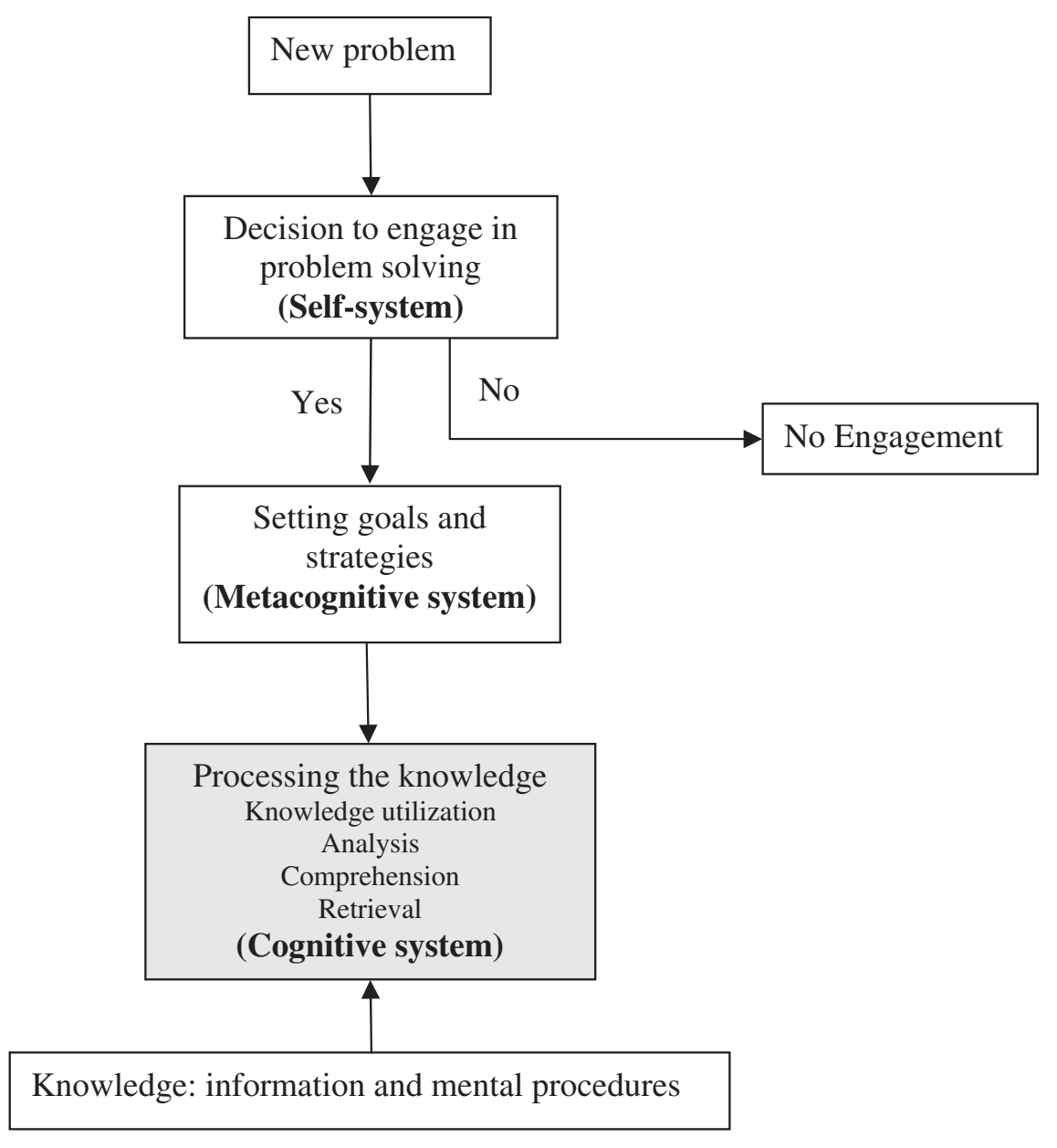

FIG. 1. Schematic diagram of the model of behavior implied in NTEO [26]. Note that TIPP currently only focuses on the interaction between the cognitive system and the knowledge. Reproduced from Ref. [26] with permission. 
TABLE III. How we map the cognitive processes suggested for classroom practice [5] with the ones from NTEO (used in TIPP).

\begin{tabular}{ll}
\hline \hline Cognitive processes recommended for physics instruction [5] & Corresponding cognitive processes in TIPP [26] \\
\hline Summarize, plan, strategize & Integrating (2a) \\
Explain, describe, depict, seek alternative representations & Symbolizing (2b) \\
Compare, contrast, categorize & Matching (3a) \\
Classify & Classifying (3b) \\
Discuss, justify, evaluate & Analyzing errors (3c) \\
Observe, extend the context, generate multiple solutions & Generalizing (3d) \\
Predict & Specifying (3e) \\
Monitor and refine communication & Metacognition (5) \\
Reflect, think about thinking, and learning & Metacognition (5) \\
Model & Combines many processes from NTEO \\
\hline \hline
\end{tabular}

not provide many details about a certain verb, we based our mapping on the frequent use of that verb in the physics classes.

Tuminaro and Redish [20] observed students solving physics problems and identified the following approaches (called epistemic games) that students choose to follow when solving a physics problem: (1) mapping meaning to mathematics, (2) mapping mathematics to meaning, (3) physical mechanism game, (4) pictorial analysis, (5) recursive plug and chug, and (6) transliteration to mathematics. Each of those approaches involves a certain set of cognitive processes that are presented in Table IV.

TABLE IV. Mapping the cognitive processes used during problem solving [20] with the ones from NTEO (used in TIPP).

\begin{tabular}{|c|c|c|}
\hline Epistemic games & $\begin{array}{l}\text { Cognitive processes that take place } \\
\text { during problem solving [20] }\end{array}$ & $\begin{array}{c}\text { Corresponding cognitive } \\
\text { processes used in TIPP [26] }\end{array}$ \\
\hline Mapping meaning to mathematics & $\begin{array}{l}\text { Develop story about physical situations } \\
\text { Translate quantities into mathematical entities } \\
\text { Relate mathematical entities in accordance } \\
\text { with physical story } \\
\text { Manipulate symbols } \\
\text { Evaluate story }\end{array}$ & $\begin{array}{l}\text { Symbolizing (2b) } \\
\text { Symbolizing (2b) } \\
\text { Symbolizing (2b) } \\
\text { Execution (1b) } \\
\text { Analyzing errors (3c) }\end{array}$ \\
\hline Mapping mathematics to meaning & $\begin{array}{l}\text { Identify target concepts } \\
\text { Find an equation relating target to concepts } \\
\text { Tell story using this relationship between concepts } \\
\text { Evaluate story }\end{array}$ & $\begin{array}{l}\text { Integrating }(2 a) \\
\text { Integrating }(2 a) \\
\text { Symbolizing }(2 b) \\
\text { Analyzing errors }(3 c)\end{array}$ \\
\hline Physical mechanism & $\begin{array}{l}\text { Develop story about physical situation } \\
\text { Evaluate story }\end{array}$ & $\begin{array}{l}\text { Symbolizing }(2 b) \\
\text { Analyzing errors }(3 c)\end{array}$ \\
\hline Pictorial analysis & $\begin{array}{l}\text { Identify target concept } \\
\text { Choose external representation } \\
\text { Tell a conceptual story based on spatial relations } \\
\text { among objects } \\
\text { Fill in the "slots" in the representation }\end{array}$ & $\begin{array}{l}\text { Symbolizing }(2 \mathrm{~b}) \\
\text { Symbolizing }(2 \mathrm{~b}) \\
\text { Symbolizing }(2 \mathrm{~b}) \\
\text { Integrating (2a) }\end{array}$ \\
\hline Recursive plug and chug & $\begin{array}{l}\text { Identify target quantity } \\
\text { Find an equation relating the target quantity with } \\
\text { other quantities } \\
\text { Determine which of the other quantities are known } \\
\text { Identify new target quantity (if necessary) } \\
\text { Calculate target quantity }\end{array}$ & $\begin{array}{l}\text { Symbolizing (2b) } \\
\text { Symbolizing }(2 b) \\
\text { Integrating (2a) } \\
\text { Integrating (2a) } \\
\text { Execution (1b) }\end{array}$ \\
\hline Transliteration to mathematics & $\begin{array}{l}\text { Identify target quantity } \\
\text { Find a solution pattern that relates to the current problem } \\
\text { Map quantities in the problem situation into the } \\
\text { solution pattern } \\
\text { Evaluate mapping }\end{array}$ & $\begin{array}{l}\text { Integrating (2a) } \\
\text { Matching (3a) } \\
\text { Matching (3a) } \\
\text { Analyzing errors (3c) }\end{array}$ \\
\hline
\end{tabular}


TABLE V. The differences between the New Taxonomy of Educational Objectives (NTEO) and the Taxonomy of Introductory Physics Problems (TIPP).

\begin{tabular}{lll}
\hline \hline Purpose & \multicolumn{1}{c}{ NTEO } & \multicolumn{1}{c}{ TIPP } \\
& $\begin{array}{l}\text { It is a framework that can be used for } \\
\text { establishing educational objectives and } \\
\text { assessments and for guiding curriculum } \\
\text { design for any subject matter. }\end{array}$ & $\begin{array}{l}\text { It is a physics problem database that gives } \\
\text { explanations and examples of problems } \\
\text { that involve certain cognitive processes. } \\
\text { This database can be used for establishing } \\
\text { educational objectives, assessments, and } \\
\text { for guiding curriculum design for } \\
\text { physics instruction. Also, it identifies } \\
\text { gaps in the available curricular material. }\end{array}$ \\
& & $\begin{array}{l}\text { Features extensions of the definitions of } \\
\text { cognitive processes applied to physics. }\end{array}$ \\
Structure & $\begin{array}{l}\text { Features general definitions of the } \\
\text { thinking processes involved in learning. } \\
\text { Features examples of tasks from a } \\
\text { (mostly selected from existing traditional or }\end{array}$ & $\begin{array}{l}\text { research-based collections). } \\
\text { It organizes physics problems. }\end{array}$ \\
variety of subjects. & Physics instruction
\end{tabular}

In the same table we show how the component cognitive processes can be mapped into NTEO. As in the previous case, we based the mapping on the authors' explanations of the context in which the action verbs were used. For instance, "identify target concept" is mapped into "integrating" for "mapping mathematics to meaning" game because in this case students identify the relevant versus nonrelevant concepts for the problem. However, the same action is mapped into "symbolizing" for "pictorial analysis game" because in this game students use their knowledge of representations to identify the target concepts and this suggests that they should already know representations in order to decide the essential versus nonessential concepts.

TIPP essentially is an application of NTEO to the context of physics problem solving. It is a classification of physics problems based on the cognitive processes and the knowledge they involve. Both taxonomies imply the same knowledge domains and the same cognitive processes (with one exception-problem solving in NTEO is associated with overcoming obstacles in TIPP). The differences between these taxonomies are presented in Table V.

\section{METHOD OF CLASSIFICATION OF PHYSICS PROBLEMS IN TIPP}

As we have previously explained, the classification of physics problems in TIPP is done under the assumption that students have minimal exposure to the specific information, mental procedures, and cognitive processes involved in a certain problem. This is because students exposed to the same problem (or similar ones) many times engage in different processes than students who never saw the problem. We do not assert that the cognitive processes presented for a certain problem are the only ones in which students engage while solving that problem. Our focus is on a set of basic processes explicitly called by the problem (e.g., a ranking task definitely involves ranking). Additionally, while we adopt the hierarchical organization of processes from the NTEO, we strongly believe that more research on student behavior has to be done to validate the relationship between the cognitive processes that are activated during physics problem solving.

In TIPP a certain problem is classified according to two criteria:

- the type of knowledge involved in the problem; knowledge here comprises information and mental procedures,

- the highest complex cognitive process that is necessary to solve it (for both information and mental procedures).

Example problem: A cart of mass $m$ moves with a speed $v$ on a frictionless air track and collides with an identical car that is stationary. If the two carts stick together after the collision, what is the final kinetic energy of the system?

A student required to solve this problem would process the knowledge (information and mental procedures) in different ways.

Concerning information, the student has to

- recall the concepts of mass, velocity, momentum, and kinetic energy;

- decide what are the key elements that need to be taken into account are (integrate the facts);

- represent the information (symbolize the facts).

Regarding mental procedures, the student needs to execute the algorithms of drawing the appropriate picture, 
writing the conservation of momentum law, solving for velocity and calculating the kinetic energy.

In conclusion, in TIPP this problem would have the designation (I:2, MP:1), indicating that the highest cognitive process required with regard to information (I) is symbolizing (level 2) and with regard to mental procedures (MP) is executing (level 1) (see Table II). For instructional needs, we find that a classification taking into account the type of knowledge and the highest complex cognitive process required to solve the problem is often enough. However, for research and assessment purposes, a finergrained characterization of physics problems would be needed, which also includes the number of cognitive processes and the knowledge subcategories featured in Table I.

\section{CHARACTERISTICS OF PHYSICS PROBLEMS GIVEN BY THE HIGHEST LEVEL OF COGNITIVE PROCESSING}

In this section, we first define the cognitive processes and then specify how they act on physics information and mental procedures. For each case, we also give examples of physics problems that trigger such processes. The definitions of the different cognitive processes are taken directly from NTEO [26]. The explanations of how these cognitive processes act on physics information and mental procedures constitute our adaptation of NTEO to physics. The examples provided reflect the way we think about how physics problems activate these processes. They also reflect the way we use them in TIPP. We do not imply that all types of problems presented in this section have to be offered to students. We rely on the instructors' teaching experience to choose the problems most suitable for their students.

Before we present the examples in this section, we want to remind the reader that each cognitive process operates on both the information and the mental procedures involved in a physics problem. As a general rule, "information problems" focus on the content knowledge, while "mental procedures" problems focus on how would one solve the problem.

\section{A. Level 1: Retrieval}

(1a) Recalling and recognizing.-Producing or recognizing basic physics knowledge related to the problem (but not necessarily understanding the structure of the knowledge).

Recalling and recognizing of physics information.-The student can define, identify, list, name, recognize, and write physical quantities, their units, basic equations, formulas, physics vocabulary terms, concepts, symbols, and phenomena. The student can state general physics laws and principles, write their corresponding equations, and identify and recognize their real-world applicability.
Physics problems involving recalling or recognizing of information.-The problems belonging to this category are designed to verify students' physics background knowledge. They do not involve mathematical manipulations. They are mostly conceptual, simple, and have a straightforward answer. Their only purpose is to verify that the student knows the minimum necessary physics information. The student should be able to answer these questions by simply recalling the content of physics laws and the definitions of different physical quantities, without doing calculations. This type of problem is very well represented in the textbooks.

Example

- Identify which of the following quantities are scalars and which are vectors: velocity, force, temperature, and mass.

Recalling and recognizing of physics mental procedures. - The student can define, identify, list, name, and recognize the situation when a physics-related mental procedure should be applied.

Physics problems involving recalling or recognizing of mental procedures.-The problems from this category are designed to develop students' ability to describe the purpose and the range of applicability of each of the mental procedures used in physics. They do not ask students to perform any of them; therefore, the students may not know how to perform them. Their only purpose is to verify that the student possesses the minimum knowledge related to mental procedures, namely when do they apply and what is the purpose for which we use each of them. The student should be able to answer those questions just by simply recalling the surface features of the mental procedures without knowing details of their execution. This kind of problem is mostly missing from the textbooks but is acknowledged in PER papers [5].

Example

- A mass slides down a frictionless circular track of radius $R$. Which of the following would let you most effectively find its angular velocity relative to the center of curvature when it reaches the bottom? [5]
(a) Kinematics only
(b) $F=m a$ or Newton's laws
(c) Work-energy theorem
(d) Impulse-momentum theorem
(e) Angular impulse-angular momentum theorem
(f) More than one of the above
(g) None of the above.

(1b) Executing.-Performing a procedure or task needed to solve the problem without significant error (but not necessarily understanding how and why the procedure works). This is not applicable to information; it applies only to mental procedures.

Executing physics mental procedures.-The student can calculate and compute different physical quantities, derive 
physics results, draw free-body diagrams, graph, plot physical quantities, and solve physics-related equations.

Physics problems involving executing of mental procedures.-To solve this class of problem, the students need to know how to perform the mental procedures particular to physics problem solving (e.g., solve mathematical equations, calculate different physical quantities using their definition, and so on). Problems involving execution are the standard problems offered in all the textbooks and extensively used in both traditional and research-based instruction. In PER they are sometimes referred to as regular problems [7].

\section{Example}

- An engine pulls a train of 20 freight cars, each having a mass of $5.14 \times 10^{4} \mathrm{~kg}$, with a constant force. The cars move from rest to a speed of $3.73 \mathrm{~m} / \mathrm{s}$ in $18.0 \mathrm{~s}$ on a straight track. Neglecting friction, what is the force with which the tenth car pulls the eleventh one (at the middle of the train)? [31]

\section{B. Level 2: Comprehension}

(2a) Integrating.--Identifying the basic structure of the physics knowledge and separating the critical from the noncritical characteristics of the problem.

Integrating physics information.-The student can isolate, separate, extract, identify, and select the relevant physics information. The student can identify, point out, and indicate defining attributes and characteristics of a physics principle or a generalization (e.g., the domain of availability, the consequences, and the degree of generality).

Physics problems involving integrating information.Problems in this category require students to be able to identify the physics information relevant for solving the problem. The PER community has created and extensively documented this kind of problem and they have been adopted in recent editions of most textbooks. Contextrich problems [9], UW tutorials [6], UM tutorials [32], the section For discussion from Hobson [33], comprehensive problems from Giambattista et al. [31], and integrated concept problems from Urone [34] belong to this category.

Example

- While on a vacation in Kenya, you visit the port city of Mombasa on the Indian Ocean. On the coast you find an old Portuguese fort probably built in the 16th century. Large stone walls rise vertically from the shore to protect the fort from cannon fire from pirate ships. Walking around on the ramparts, you find the fort's cannons mounted such that they fire horizontally out of holes near the top of the walls facing the ocean. Leaning out of one of these gun holes, you drop a rock which hits the ocean $3 \mathrm{~s}$ later. You wonder how close a pirate ship would have to sail to the fort to be in range of the fort's cannon. Of course you realize that the range depends on the velocity with which the cannonball leaves the cannon. That impact velocity depends, in turn, on how much gunpowder was loaded into the cannon. Calculate the muzzle velocity necessary to hit a pirate ship $300 \mathrm{~m}$ from the base of the fort [32].

Integrating physics mental procedures. - The student can point out, indicate, design, determine, discuss, explain, illustrate, list, name, organize, outline, sketch, summarize, and write the steps involved in a mental procedure selecting (separating) the essential from nonessential ones. The students can formulate and plan a strategy for solving the problem.

Physics problems involving integrating mental procedures.-The problems in this category ask students to outline a strategy, or to simplify a given strategy that contains too many unnecessary steps, or to complete a given strategy that is not complete. This category of problem is poorly represented in the traditional introductory physics textbooks and research. Although the example problems in most textbooks contain explicit problemsolving strategies, the textbooks rarely offer exercises that ask students to write a strategy by themselves. There are some context-rich problems [9] that involve integration of mental procedures.

\section{Example}

- At time $t=0$, block A of mass $0.225 \mathrm{~kg}$ and block B of mass $0.600 \mathrm{~kg}$ rest on a frictionless surface a distance $3.4 \mathrm{~m}$ apart, with block A located to the left of block B. A horizontal force of $2.00 \mathrm{~N}$ directed to the right is applied to block A for a time interval $\Delta t=0.1 \mathrm{~s}$. During the same time interval, a $5.0 \mathrm{~N}$ horizontal force directed to the left is applied to block B. How far from B's initial position do the two blocks meet? How much time has elapsed from $t=0$ until the blocks meet? A) Write a strategy to solve this problem. B) Use your strategy to solve the problem. (Adapted from Giambattista et al. [31].)

(2b) Symbolizing.-Constructing an accurate symbolic image of the information or mental procedure needed to solve the physics problem.

Symbolizing physics information.-The student can represent pictorially, verbally, mathematically, or graphically physical quantities, basic equations, formulas, physics vocabulary terms, concepts, symbols, and phenomena.

Physics problems that involve symbolizing information.-Any problem that involves equations, diagrams, plots, or drawings belongs to this category. This class of problem is very well represented in textbooks and it has been comprehensively studied by physics education researchers. The following are a few researchbased collections of symbolizing of information physics problems: pose a problem [7,35], diagram jeopardy [7], equation jeopardy [7], represent and reason [7], changing representation tasks [8], jeopardy problems [36,37], UW tutorials [6], UM tutorials [32], context-rich problems [9], multiple representation tasks [8,38], working backwards tasks [8], and problems that develop symbolic reasoning [37]. 
Example

- A stoplight turns yellow when you are $20 \mathrm{~m}$ from the edge of the intersection. Your car is traveling at $12 \mathrm{~m} / \mathrm{s}$. After you hit the brakes, your car's speed decreases at a rate of $6 \mathrm{~m} / \mathrm{s}$ each second. Sketch the situation. Draw a motion diagram. Draw an $x(t)$ graph. Draw a $v(t)$ graph. Write $x(t)$ and $v(t)$ expressions [7].

Symbolizing physics mental procedures.-The student can represent, illustrate, and map the component parts of the mental procedures involved in a problem.

Physics problems that involve symbolizing mental procedures.-This group of problems asks students to create diagrams, concept maps, or flow charts that indicate each component of the mental procedure involved in a certain problem in the order in which they have to be performed. Representation of mental procedures problems are almost nonexistent in textbooks and poorly represented in PER literature.

Example

- You are given the following problem. You don't need to solve it. You only need to create a flow chart to illustrate the steps you are going to follow to find the answers.

Problem: The coefficient of static friction between a block and a horizontal floor is 0.35 , while the coefficient of kinetic friction is 0.22 . The mass of the block is $4.6 \mathrm{~kg}$ and it is initially at rest. (a) What is the minimum horizontal applied force required to make the block start to slide? (b) Once the block is sliding, if you keep pushing on it with the same minimum starting force as in part (a), does the block move with constant velocity or does it accelerate? (c) If it moves with constant velocity, what is its velocity and if it accelerates, what is its acceleration?

\section{Level 3: Analysis}

(3a) Matching.-Identifying similarities and differences and relationships between the physics problem components.

Critical characteristics of effective matching are

- specifying the attributes or characteristics according to which items being ranked are to be analyzed,

- determining how they are alike and different,

- stating similarities and differences as precisely as possible.

Matching physics information.-The student can compare, arrange, differentiate, distinguish, match, rank, order, and reorder magnitudes of physical quantities. The student can compare physics phenomena, equations, and physicsrelated statements and is able to find similarities and differences between them. He of she can arrange, categorize, and group specific details into meaningful categories. The student can identify in what aspect a principle or generalization is similar to and/or different from other generalizations or principles.
Physics problems involving matching of information.The problems from this category ask the students to compare magnitudes of physical quantities, physics phenomena, and physics-related statements. Ranking of information problems are scarcely offered in physics textbooks, but there exist research-based collections of them. Ranking problems [39,40], UW tutorials [6], UM tutorials [32], and comparison tasks [8] contain such problems.

Example

- Rank these cases from the highest to the lowest acceleration based on the drawings shown in Fig. 2. Assume all accelerations are constant and use the coordinate system specified in the drawing. Note: zero is greater than negative acceleration, and ties are possible [39].

Matching physics mental procedures.-The student can compare, arrange, differentiate, distinguish, match, rank, order, and reorder mental procedures. The student can identify in what aspect a mental procedure is similar to and/or different from another mental procedure.

Physics problems involving matching of mental procedures.-The problems from this category ask the students to compare and organize mental procedures in categories based on similarities and differences between them. This category of problem is rarely present in textbooks and PER material makes only a few references to such problems $[5,41,42]$.

Example

- You are given the following problem. You don't need to solve it. You only need to describe the similarities and the differences between a problem-solving approach that involves energy concepts and one that involves kinematics concepts.

Problem: A $1.19 \mathrm{~kg}$ hollow ball with a radius of $0.132 \mathrm{~m}$, filled with air, is released from rest at the bottom of a $1.80 \mathrm{~m}$ deep pool of water. How high above the water does the ball shoot upward? Neglect all frictional effects, and neglect the ball's motion when it is only partially submerged.

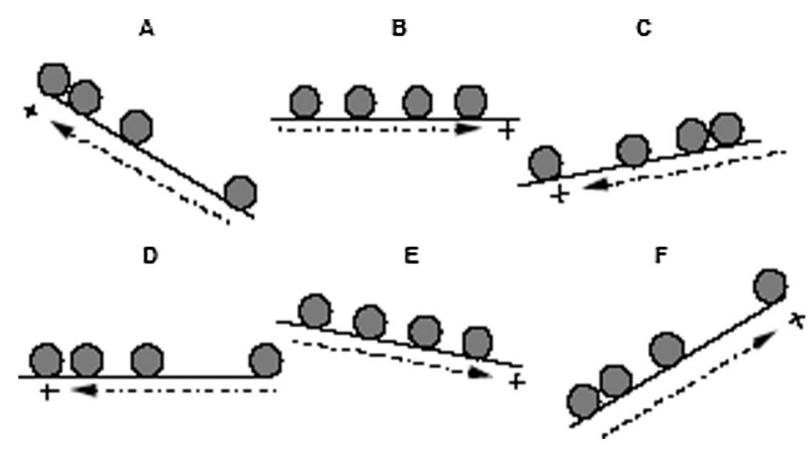

FIG. 2. Motion diagrams. 
(3b) Classifying.-Identifying superordinate and subordinate categories into which physics knowledge related to a problem can be organized.

An effective classification is based on

- identification of the defining characteristics of the items to be classified,

- identification of a superordinate category to which the item belongs and explaining why it belongs to that category,

- identification of one or more (if any) subordinate categories for the item and explaining how they are related.

The particular feature of classification is that it contains both superordinate and subordinate categories, as opposed to the categorization done in matching which was pure organization of knowledge in groups and categories without relating to sub- or superordinate categories.

Note: In physics, the cognitive process of classification is not widely used in the instruction. However, in life sciences like biology and anatomy, the instruction is largely based on it. The well-known tree of life is just one example of information structured using classification.

Classifying physics information.-The student can identify, determine, indicate, and label the general subordinate and superordinate categories to which specific information belongs. For a certain physics principle, the student can identify a superordinate category to which it belongs and deduce its consequences and applications.

Physics problems involving classification of physics information.-Those problems ask students to classify physics information (e.g., definitions, equations, physical quantities, concepts, laws, principles, physical configurations, physics systems) according to different criteria. Classification of information physics problems are almost totally absent from current textbooks. Some of the ALPS kits [43] make use of classification.

Example

- We have been studying Bernoulli's law. Identify a class of general laws to which it belongs. Explain the features of Bernoulli's law that make it a member of the category you have identified. This law has multiple applications. Describe two or more categories of these applications [26].

Classifying physics mental procedures.-The student can identify superordinate and subordinate categories of mental procedures. The student can determine, discuss, evaluate, explain, identify, and indicate the degree of generality of the mental procedures used in physics problems.

Physics problems involving classification of physics information.-The problems from this category ask the students to classify mental procedures or classify problems according to similarities in their solutions indicating superordinate and subordinate categories. The purpose of these problems is to train the students in building hierarchical classifications of the problem-solving procedures used in physics. Such problems are rarely available in current textbooks or research-developed collections of problems.

\section{Example}

- Classify the solving strategy involved in the problem given below within the kinematics problem-solving strategies. Make sure to include superordinate and subordinate categories in your classification.

Problem: A model rocket is launched straight upward with an initial speed of $49.5 \mathrm{~m} / \mathrm{s}$. It accelerates with a constant upward acceleration of $2.03 \mathrm{~m} / \mathrm{s}$ [2] until its engines stop at an altitude of $149 \mathrm{~m}$. What is the maximum height reached by the rocket? How long after lift-off does the rocket reach its maximum height? How long is the rocket in the air?

A possible answer: The mental procedures used to solve this problem are the ones that apply to motion with constant acceleration. This problem is a combination of two types of motion with constant acceleration: free fall and motion with constant acceleration different than $g$. The diagram presented in Fig. 3 shows where the solving strategies for this problem are situated within the kinematics problem-solving strategies.

(3c) Analyzing errors.-Analyzing the logic, the reasonableness, and the accuracy of physics knowledge.

Analyzing errors is based on

- consciously judging the validity of the knowledge based on explicit criteria,

- identifying any errors in reasoning that have been presented.

Analyzing errors related to physics information.-The student can determine, demonstrate, argue, assess, check, discuss, explain, illustrate, and judge the reasonableness of the information regarding specific details, generalizations and principles.

Physics problems involving analyzing errors related to information.-This type of problem is designed to emphasize that "properly applied physics must describe nature accurately and is not simply the process of solving equations" [34]. Those problems can contain data, assumptions, or arguments that can produce an unreasonable result. Or they can refer to a situation with which the students are usually not familiar and the result is reasonable but hard to believe. They can also involve estimations. Or the students are given a research question and some information and they need to decide how much more information they need, where and how they can find it, and how to operate on it to find the answer. Estimation problems are offered in any textbook. In addition, some of the textbooks included other types of analyzing errors problems like unreasonable results problems [34]. The PER community has been very productive in developing this class of problems. Here are some PER collections: $U W$ tutorials [6], UM tutorials [32], context-rich problems [9], picture and translate [7], what, if anything, is wrong 


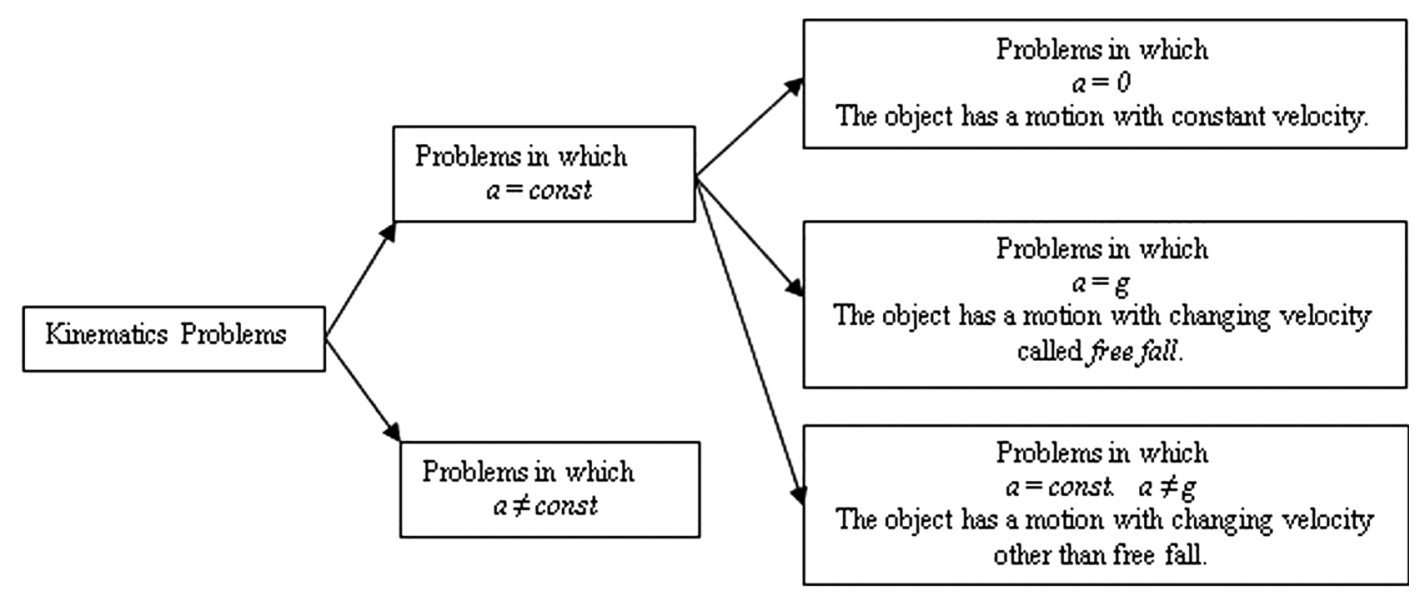

FIG. 3. Possible classification scheme for kinematics problems.

tasks [8], troubleshooting tasks [8], case study problems [44], insufficient or excess information problems [45], conflicting contention tasks [8], and guesstimation [46].

\section{Example}

- Body fat is metabolized, supplying $9.3 \mathrm{kcal} / \mathrm{g}$, when dietary intake is less than needed. The manufacturers of an exercise bicycle claim that you lose $1 \mathrm{lb}$ of fat per day by vigorously exercising for $2 \mathrm{~h}$ per day on their machine. (a) How many kcal are supplied by the metabolization of $1 \mathrm{lb}$ of fat? (b) Calculate the $\mathrm{kcal} / \mathrm{min}$ that you would have to utilize to metabolize fat at a rate of $1 \mathrm{lb}$ in $2 \mathrm{~h}$. (c) What is unreasonable about the results? (d) Which premise is unreasonable, or which premises are inconsistent? [34]

Analyzing errors related to physics mental procedures.-The student can identify errors made during the execution of a mental procedure.

Physics problems involving analyzing errors related to mental procedures.-These problems ask students to identify errors or missing elements in the execution or presentation of the mental procedures. Evaluate the solution [7] and WRONG (What's remiss or not good) problems [8], evaluation problems [47,48], and evaluation tasks [49] are some research-based collections of problems that involve analyzing errors related to mental procedures.

\section{Example}

- A 1000-kg elevator is moving down at $6 \mathrm{~m} / \mathrm{s}$. It slows to a stop in $3 \mathrm{~m}$ as it approaches the ground floor. Determine the force that the cable supporting the elevator exerts on the elevator as the elevator stops (Fig. 4). You are given a proposed solution. Verify if the solution is correct. If yes, acknowledge this. If not, correct it [7].

Proposed solution: The elevator is the object of interest. It is considered a particle and the forces that other objects exert on the elevator are shown in the free-body diagram.
The acceleration of the elevator is $a=v_{0}^{2} / 2 d=$ $(6 \mathrm{~m} / \mathrm{s})^{2} / 2(3 \mathrm{~m})=6 \mathrm{~m} / \mathrm{s}^{2}$.

The force of the cable on the elevator while stopping is $T=m a=(1000 \mathrm{~kg})\left(6 \mathrm{~m} / \mathrm{s}^{2}\right)=6000 \mathrm{~N}$.

(3d) Generalizing.-Constructing new generalizations or principles from available physics knowledge.

Generalization involves

- focusing on specific pieces of information or observations without making assumptions,

- looking for patterns or connections in the information,

- making a general statement that explains the patterns or connections.

Generalizing physics information.-The student can construct and defend generalizations and principles based on given details. When exposed to principles and generalizations, the student can construct principles and generalizations with a higher degree of generality than the given ones.

Physics problems involving generalization of physics information.-This kind of problem asks the student to

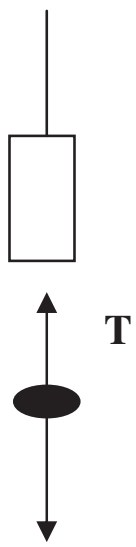

FIG. 4. Object suspended in an elevator. 
generalize results, statements, and equations. While solving them, the students discover that most of the physics equations, statements, and conclusions are consequences of relatively few principles and generalizations. Those problems can be used to emphasize the coherence of physics knowledge by training students to transfer the knowledge from the details to more general principles. Neither textbooks nor PER literature contain a significant number of such problems.

Example

- In Fig. 5 objects in different physical configurations are given. For each system, draw a free-body diagram. By inspecting the normal force in each case, construct a description of it as completely (general) as you can. Note that there are two scenarios described below.

(1) All the following objects are in equilibrium on surfaces with friction (Fig. 5).

(2) Consider a man sitting on a scale in an elevator moving up with an acceleration $a$.

A possible answer: The normal force is always perpendicular to the contact surface. Its magnitude can be greater than, less than, or equal to the weight of the object. Its direction can be vertical, horizontal, or oblique. It acts both on objects in equilibrium and on objects not in equilibrium. It acts both in inertial systems and in noninertial systems.

Generalizing physics mental procedures.-The student can construct and defend general conclusions about mental procedures.

Physics problems involving generalization of mental procedures.-The problems from this category ask the students to create generalizations related to mental procedures. Neither textbooks nor PER literature contain a significant number of such problems. Catrambone [50] discovered that offering students worked examples labeled according to generalized solution procedures had beneficial learning impact on student learning.

Example

- Create a general procedure to solve kinematics problems that also involve dynamics. (Adapted from Knight [51].)
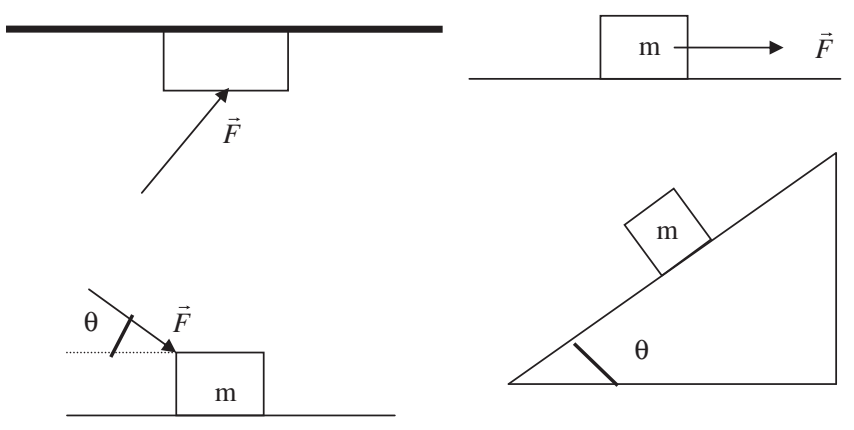

FIG. 5. Objects in equilibrium on surfaces with friction.
A possible solution: Here is a possible six-point plan designed specifically for problems that involve translational kinematics and dynamics.

First impression: Summarize the physics information given in the problem. (Specify if the problem refers to an $a=$ const or to an $a \neq$ const case. Specify if the force is given, is required, or it is not important in the problem.) Assignments: Decide what is known and what is unknown.

Drawing: Make simplifying assumptions (e.g., the body is a box). Sketch important points in the motion, establish a coordinate system, and include the relevant physics information (distances, velocities, acceleration). Strategy: Specify the plan that you are going to follow to solve the problem. Use Newton's 2nd law to find the net force. Depending on the problem, either (a) solve for the acceleration, then use kinematics to find velocities and positions, or (b) use kinematics to determine acceleration, then solve for the unknown forces.

Solution: Solve the equations algebraically and find the required quantities.

Answer: Plug in numbers and calculate the numerical value. Make sure you include units and check if your answer is reasonable.

(3e) Specifying.-Generating new applications or logical consequences from available physics knowledge.

Critical attributes of specifying are

- identifying the generalizations or principles that apply to a specific situation,

- making sure that the specific situation meets the conditions for principles to apply,

- if the generalizations or principles do apply, identifying what conclusions can be drawn or what predictions can be made.

Specifying physics information.-The student can identify characteristics that might be true or must be true under certain conditions relative to a given generalization. The student can make (infer) predictions about what might happen or must happen under certain conditions relative to a given principle.

Physics problem involving specifying physics information.-The problems from this category ask the student to apply known principles and generalizations to new specific situations. Problems requiring predictions belong to this category as well. Textbooks do not contain a significant number of such problems. Predict and explain tasks [8], UW tutorials [6], and UM tutorials [32] belong to this category.

Example

- A golfer is trying to hit a golf ball onto the green. The green is a horizontal distance $s$ from the tee and it is up on the side of a hill a height $h$ above his tee. When he strikes the ball it leaves the tee at an angle $\theta$ to the horizontal. He wants to know with what speed, $v_{0}$, the ball must leave the tee in order to reach the height $h$ at the distance $s$. 
(a) Once he has struck the ball, what controls its motion? Write the equations that determine the vector acceleration of the golf ball after it leaves the tee. Be sure to specify your coordinate system. For this part of the problem you may ignore air resistance.

(b) Solve the equations you have written in (a) to obtain expressions which can be evaluated to give the position of the ball at any time, $t$.

(c) If the golfer wants his ball to land in the right place, he must hit it so that it leaves the tee with the right speed. Explain how he can calculate it. (Again, you may ignore air resistance.) Find an equation for the initial speed in terms of the problem's givens.

(d) If the ball leaves the tee at an angle of $30^{\circ}$, and $s=100 \mathrm{~m}, h=10 \mathrm{~m}$, find the speed with which the ball should leave the tee.

(e) Now consider the effect of air resistance. Suppose that a good model for the force of air resistance is the Newton drag law, $\mathbf{F}=-b|\mathbf{v}| \mathbf{v}$, where $|\mathbf{v}|$ stands for the absolute value of the velocitythe speed. Consider three points of the ball's trajectory: halfway up, at its highest point, and halfway down. Discuss the direction of the resistance force at each place. Qualitatively (do not attempt a calculation), what will the effect of air resistance be on the ball's motion? [32]

Specifying physics mental procedures.-The student can defend and make inferences about what might happen or must happen under certain conditions relative to a mental procedure. The student is able to explain how the usage of a certain mental procedure helped him or her make a prediction.

Physics problems involving specifying mental procedures.-The problems belonging to this category ask the students to predict what would happen during the execution of a mental procedure if some conditions are changed (e.g., if the initial conditions are changed, if it is not allowed to use a certain law or principle, or certain diagrams). Neither textbooks nor PER literature contain a significant number of such problems.

\section{Example}

- Specify how the procedure of calculating the momentum and the kinetic energy of a classical particle change when the particle becomes relativistic. Clearly indicate the differences between the treatment of a classical and a relativistic particle.

\section{Level 4: Knowledge utilization}

(4a) Decision making.-Selecting between two or more alternatives.

Decision making regarding physics information.-The student can make decisions regarding details, principles, and generalizations.
Physics problems involving decision making of physics information.-This kind of problem requires the student to make a decision. The problems here do not refer to a basic, simple decision that, to some extent, is present in any physics problem. They refer to complicated and not always obvious decisions for which the student has to go through other lower-level cognitive processes and operate upon a large amount of knowledge. Such problems are presented in some textbooks [34] and in some PER collections [9].

Example

- A car advertisement claims that its $900-\mathrm{kg}$ car can accelerate from rest to $30 \mathrm{~m} / \mathrm{s}$ driving $100 \mathrm{~km}$ gaining $3 \mathrm{~km}$ in altitude while burning $1 \mathrm{gal}$ of gasoline. The average force of friction including air resistance is $700 \mathrm{~N}$. Will you buy this car? Or do you think this is not possible and the company fools the people who don't know physics? [34]

Decision making regarding physics mental procedures.-The student uses his or her skills or knowledge of a mental procedure to make decisions regarding mental procedures.

Physics problems involving decision making of mental procedures.-Those problems ask the student to make decisions about mental procedures and explain how they made their decisions. Some context-rich problems [9] belong to this category. Textbooks do not contain a significant number of such problems.

Example

- Sam, whose mass is $75 \mathrm{~kg}$, straps on his skis and starts down a 50-m-high, $20^{\circ}$ bumpy frictionless slope. A strong headwind exerts a horizontal force of $200 \mathrm{~N}$ on him as he skis. Find Sam's speed at the bottom (a) using work and energy, (b) using Newton's laws. Decide which method is the most straightforward and the easiest to work with. Explain your decision. (Modified from Knight [51].)

(4b) Overcoming obstacles (problem solving).Accomplishing a goal or a task for which obstacles or limiting conditions exist.

Overcoming obstacles involves

- identifying obstacles to the goal,

- identifying alternative ways to accomplish the goal,

- evaluating the alternatives,

- selecting and executing the alternatives.

Note: The name of this level used by Marzano and Kendall [26] is "problem solving." We renamed it "overcoming obstacles" because we think that pen-and-paper problem solving can also include the following levels(4c) experimenting and (4d) investigating. We have identified problems that involve such processes and, consequently, we think that, from the perspective of the existing problems, the problem-solving process cannot be a level lower than (4c) experimenting and (4d) investigating. Instead, it should be above them. 
Overcoming obstacles related to physics information.The student can solve any of the problems that deal with lower-level cognitive processes that now have constraints. The student uses his or her knowledge of information to overcome an obstacle presented in the problem.

Physics problems that involve overcoming obstacles related to information.-Those problems are any of the previously described problems in which certain obstacles have been introduced. Also they can involve combinations of obstacles presented in the previous levels (e.g., estimations, underinformed problems, etc.). The students need to use their knowledge to overcome the obstacles. Neither textbooks nor PER literature contain a significant number of such problems.

Example

- We used kinematics and Newton's 2nd law to solve in-class problems involving elevators in uniform and accelerated motion. Now, solve the following elevator problem that embeds three obstacles: (a) this time the motion of the elevator is a combination of uniform and accelerated motion, (b) you have to estimate the quantities you'll need because they are not given in the problem, and (c) you have to solve the problem in two ways.

Problem: Officials at Otis Elevator Company are concerned that their elevators in an expensive hotel are running too slowly. They ask you to estimate the starting and stopping acceleration and the speed when moving at constant speed between stops. They want you to provide at least two methods of finding all of the above, detailed calculations for each of them and comparative analysis of your results. (Adapted from Van Heuvelen and Etkina [7].)

Overcoming obstacles related to physics mental procedures.-The student uses his or her knowledge of a mental procedure to overcome an obstacle.

Physics problems that involve overcoming obstacles related to mental procedures.-The problems from this category are regular problems in which constraints regarding mental procedures have been introduced. Neither textbooks nor PER literature contain a significant number of such problems.

Example

- You are asked to hang a uniform beam and sign using a cable that breaks when the tension exceeds $T$. The store owner asks that it hang out over the sidewalk as shown in Fig. 6. The sign has a weight of $W_{\text {sign }}$ and the beam's weight is $W_{\text {beam }}$. The beam's length is $l$ and the sign's dimensions are $x$ (horizontally) and $y$ (vertically). What is the minimum angle $\theta$ that you can have between the beam and the cable, so that the cable does not break?

We solved this problem in class by choosing the axis of rotation at $\mathrm{C}$ and by calculating the torque using $\tau=r_{\perp} F$.

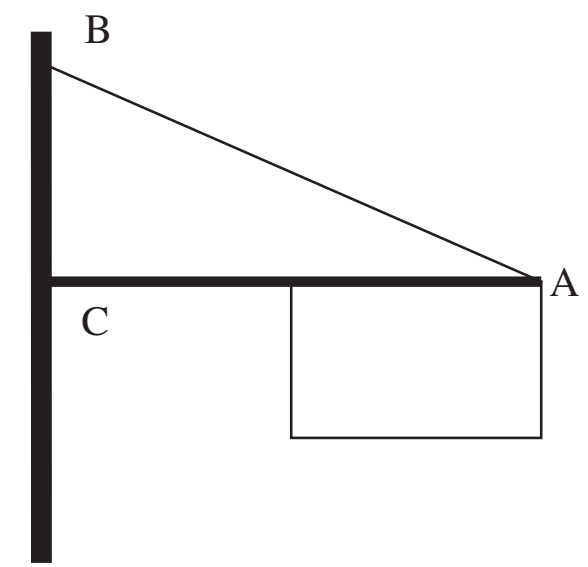

FIG. 6. Store sign supported by a cable.

Now, you have to solve the problem with the following constraints: (a) by choosing a rotation axis situated at A and calculating the torque using $\tau=r_{\perp} F$ and (b) by choosing the axis of rotation at $\mathrm{B}$ and calculating the torque using $\tau=r F_{\perp}$. Indicate one more method to calculate $\theta$.

(4c) Experimenting.-Generating and testing hypotheses for the purpose of understanding phenomena, using rules of evidence that adhere to statistical hypothesis testing.

Experimenting requires

- making predictions based on known or hypothesized principles,

- designing a way to test the predictions,

- evaluating the validity of the principles based on the outcome of the test.

Experimenting related to physics information.-The student uses his or her knowledge of information to generate and test hypotheses regarding physics information. More concretely, the student makes predictions based on known or hypothesized physics principles, designs ways to test the predictions, and evaluates the validity of the principles based on the outcome of the test.

Physics problems involving experimenting related to physics information.-In those problems, the student observes a phenomenon, collects the data (or is given a collection of data), and creates and tests hypotheses about certain scientific truths. Predict and test [7], design problems [37], and experiment problems [52,53] are some examples of such problems.

Example

- A bead attached to a vertical string swings periodically with small amplitude. Four students argue about what might influence the period of this motion.

Carl believes that the period increases only if the mass of the bead increases. Dan believes that the period decreases only if the mass of the bead increases. Esther says that the period increases only if the length 
of the string decreases. Frank believes that the period increases only if the length of the string increases.

(a) Describe an experiment that the students can perform to test their hypotheses.

(b) Describe what each student would predict based on their hypotheses.

Maria attached different beads of volume $V=10 \mathrm{~cm}$ [3] to inextensible strings of identical material but different lengths and let them swing. Table VI shows the data collected by Maria during this experiment. Examine the data table. Use your knowledge of statistics to determine what judgment will the students be able to make about their hypotheses based on this data. Explain.

Experimenting related to physics mental procedures.The student uses his or her knowledge of a mental procedure to generate and test hypotheses or generates and tests hypotheses regarding physics-related mental procedures.

Physics problems involving experimenting related to mental procedures.-Those problems ask the students to use mental procedures along with information to generate and test hypotheses about mental procedures. Neither textbooks nor PER literature contain a significant number of such problems.

Example

- Carl and Tara argue about the best method to determine the density of an object.

Carl believes that the best method is (1) to weigh the object and find its mass, (2) then measure its dimensions and calculate the volume, and (3) find density using density definition $\rho=m / V$.

Tara argues that the best method is (1) to weigh the object in air and then in water, (2) then use Newton's 2nd law and density definition $\rho=m / V$ to determine that $\rho=\rho_{\text {water }}\left[1 /\left(1-W_{\text {water }} / W_{\text {air }}\right)\right]$, and (3) calculate $\rho$ knowing $\rho_{\text {water }}, W_{\text {water }}, W_{\text {air }}$.

Hypothesize which method is the most precise one.

TABLE VI. Oscillation period for different beads and various string lengths.

\begin{tabular}{lccc}
\hline \hline Bead material & Bead mass $(g)$ & String length $(m)$ & Period $(s)$ \\
\hline Wood & $8 \pm 0.1$ & $1 \pm 0.001$ & $1.99 \pm 0.05$ \\
Iron & $78 \pm 0.1$ & $1 \pm 0.001$ & $2.00 \pm 0.05$ \\
Copper & $89 \pm 0.1$ & $1 \pm 0.001$ & $1.98 \pm 0.05$ \\
Chromium & $72 \pm 0.1$ & $1 \pm 0.001$ & $2.01 \pm 0.05$ \\
Alloy no. 1 & $120 \pm 0.1$ & $1 \pm 0.001$ & $2.03 \pm 0.05$ \\
Alloy no. 2 & $64 \pm 0.1$ & $1 \pm 0.001$ & $1.96 \pm 0.05$ \\
Aluminum & $27 \pm 0.1$ & $1 \pm 0.001$ & $2.01 \pm 0.05$ \\
Aluminum & $27 \pm 0.1$ & $1.5 \pm 0.001$ & $2.45 \pm 0.05$ \\
Aluminum & $27 \pm 0.1$ & $0.5 \pm 0.001$ & $1.42 \pm 0.05$ \\
Aluminum & $27 \pm 0.1$ & $2 \pm 0.001$ & $2.82 \pm 0.05$ \\
Aluminum & $27 \pm 0.1$ & $0.75 \pm 0.001$ & $1.73 \pm 0.05$ \\
Aluminum & $27 \pm 0.1$ & $1.25 \pm 0.001$ & $2.23 \pm 0.05$ \\
Aluminum & $27 \pm 0.1$ & $1.75 \pm 0.001$ & $2.65 \pm 0.05$ \\
\hline \hline
\end{tabular}

TABLE VII. Results of several measurements of cube's mass and side.

\begin{tabular}{lc}
\hline \hline Mass $(\mathrm{kg})$ & Cube side $(\mathrm{cm})$ \\
\hline $0.151 \pm 0.001$ & $3.73 \pm 0.1$ \\
$0.155 \pm 0.001$ & $3.85 \pm 0.1$ \\
$0.145 \pm 0.001$ & $3.77 \pm 0.1$ \\
$0.148 \pm 0.001$ & $3.79 \pm 0.1$ \\
$0.152 \pm 0.001$ & $3.87 \pm 0.1$ \\
$0.147 \pm 0.001$ & $3.81 \pm 0.1$ \\
$0.151 \pm 0.001$ & $3.85 \pm 0.1$ \\
$0.145 \pm 0.001$ & $3.77 \pm 0.1$ \\
$0.155 \pm 0.001$ & $3.85 \pm 0.1$ \\
$0.149 \pm 0.001$ & $3.80 \pm 0.1$ \\
\hline \hline
\end{tabular}

Suppose you find in a lab manual the data shown in Tables VII and VIII about a cubic object made of aluminum. Show how you will test your hypothesis based on the given data. Use your knowledge of statistics to determine what would be the most precise method to measure the density of an object. Explain why.

(4d) Investigating.-Generating and testing hypotheses about past, present, and future events, using wellconstructed and logical arguments as evidence.

Critical attributes of investigating are

- identifying what is known or agreed upon regarding the phenomenon under investigation,

- identifying areas of confusion or controversy regarding the phenomenon,

- providing an answer for the confusion or controversy,

- presenting a logical argument for the proposed answer.

Note: Both experimenting and investigating involve creating and testing hypotheses. The difference between them is that the rules of evidence are different. The former has conclusions based on statistical testing while the latter has conclusions based on well-constructed arguments.

Investigating physics information.-The student uses his or her knowledge of information as a tool to investigate a

TABLE VIII. Results of several measurements of cube's weight in air and in water.

\begin{tabular}{lc}
\hline \hline Weight in air $(\mathrm{N})$ & Weight in water $(\mathrm{N})$ \\
\hline $1.480 \pm 0.01$ & $0.931 \pm 0.01$ \\
$1.519 \pm 0.01$ & $0.919 \pm 0.01$ \\
$1.484 \pm 0.01$ & $0.895 \pm 0.01$ \\
$1.489 \pm 0.01$ & $0.914 \pm 0.01$ \\
$1.501 \pm 0.01$ & $0.898 \pm 0.01$ \\
$1.492 \pm 0.01$ & $0.903 \pm 0.01$ \\
$1.510 \pm 0.01$ & $0.919 \pm 0.01$ \\
$1.516 \pm 0.01$ & $0.931 \pm 0.01$ \\
$1.498 \pm 0.01$ & $0.916 \pm 0.01$ \\
$1.496 \pm 0.01$ & $0.914 \pm 0.01$ \\
\hline \hline
\end{tabular}


past, present, or future event or conducts an investigation regarding information.

Physics problems involving investigating information.Those problems can directly ask the student to investigate a phenomenon and/or they can teach the student to do so by guiding student's investigation through specific questions. Investigation problems are not present in the introductory physics textbooks, but the PER community has developed them. Examples are open-ended problems [54], goal-less problem statements [55], and multiple-possibilities problems [56].

Example

- We have studied the relationship between ocean depth and polar ice caps. Using your knowledge of physics, investigate what might happen if Earth's temperature would rise by $5{ }^{\circ} \mathrm{C}[26]$.

Investigating related to physics mental procedures.The student uses his or her skill in or knowledge of a mental procedure as a tool to investigate a past, present, or future event or conducts an investigation regarding a mental procedure.

Physics problems involving investigating mental procedures.-In those problems the students create and test hypotheses using mental procedures or create and test hypotheses about mental procedures. Investigation problems are not present in the introductory physics textbooks, but the PER community has developed them. Examples are open-ended problems [54], goal-less problem statements [55], and multiple-possibilities problems [56].

\section{Example}

- Investigate whether you can apply the equations of linear motion in the case of circular motion. If yes, show how you characterize the circular motion with them. If not, build new equations that can describe the circular motion.

\section{ASSESSMENT OF TIPP VALIDITY AND RELIABILITY}

TIPP validity $[57,58]$ has been tested in three phases and involved soliciting feedback from instructors, problem developers, and physics education researchers. The requested feedback targeted the algorithm used to classify the problems, the definitions presented, and the examples provided.

Phase 1 (May 2008)-We initiated discussions about the algorithm that we use to label physics problems in TIPP and the classification of physics problems based on the highest cognitive process required to solve thembetween one graduate student and six professors (five teaching in university and one in community college). The graduate student and two professors were directly involved in the design of the taxonomy. Another professor is a respected senior professor with over 35 years of teaching experience and a renowned physics education researcher who wrote several books containing research-based physics problems. The next professor has taught physics for the past 20 years and is an active member of the PER community doing research related to classification of physics problems. The fifth professor has taught physics over the past 25 years, but was not involved in PER. The sixth professor has taught physics in the past 2 years and is becoming part of the PER community. The graduate student and the professors have been asked to answer the following questions:

(1) Is the algorithm we use for labeling the problems clear?

(2) Are the levels we describe in the previous section relevant for a taxonomy of physics problems?

(3) Are the definitions clear?

(4) Are all the levels essential? If not, what are the levels least essential and why? Are other levels missing?

(5) Are the examples provided relevant for each level?

(6) Can all introductory physics problems be classified according to the algorithm presented?

All the participants received the taxonomy and were allowed to reflect on the questions for up to three months. After this period, some of them sent their feedback by mail while others discussed with the first author in person. Unanimously, they answered "yes" to all questions and for question (4) they found the levels essential without any omissions.

Phase 2 (December 2009)—We initiated discussions with a senior physics education researcher who conducted more than 500 hours of problem-solving interviews with students. The researcher was asked to confirm if the cognitive processes used in TIPP are in fact observed and practiced by students while solving physics problems. He confirmed that students perform such processes during physics problem solving.

Phase 3 (February 2010)—We interviewed eight physics problems developers and asked them if they agree with the assigned levels for their problems. Unanimously, they agreed with our designation.

To test TIPP reliability, we focused on the classification described in Sec. III. The reliability involves calculating Cohen's kappa coefficient of inter-rater reliability agreement coefficient [59]. TIPP reliability testing had three phases.

Phase 1 (June 2007) —One graduate student and two physics professors, who participated in the development of the taxonomy, classified 80 problems from various textbooks $[31,33,51,60,61]$. The inter-rater reliability Cohen's kappa coefficient ranged between 0.82 and 0.91 .

Phase 2 (June 2008) —One graduate student and two professors classified 80 problems selected from the existing array of end-of-chapter problems from textbooks, as well as PER-inspired problems from various collections $[6,7,9,31-34,39,51,54,60,61]$. The graduate student and one professor were involved in the development of the taxonomy. The second professor had no previous contact 
with the taxonomy. The inter-rater reliability Cohen's kappa coefficient ranged between 0.75 and 0.84 .

Phase 3 (April 2009) - The same group as in phase 2 classified the same problems. The inter-rater reliability Cohen's kappa coefficient ranged between 0.70 and 0.82 .

The test-retest reliability was measured by calculating the Cohen's kappa coefficient for each of the raters at two different moments in time (June 2008 and April 2009). The Cohen's kappa coefficient ranged between 0.70 and 0.85 . The values of this coefficient suggest that there is a good level of agreement between the raters and therefore the taxonomy appears to be reliable.

In our experience in working with the taxonomy, we learned that training is necessary for achieving these values of agreement. In addition, clear assumptions about the material taught in class as well as about the problem solution have to be made before the classification. Unless specified, different instructors usually assume different levels of coverage of the same topic and different solving approaches. Without training and a clear statement of assumptions, the Cohen's kappa coefficient can drop below 0.50 . We noticed that instructors have different perceptions of problems' complexity. For some instructors, certain problems seem trivial and somehow they perceive them as "low level" for their students, while for others the same problems seem more complex. While we had to make clear assumptions before the reliability testing, we believe that TIPP will be equally useful for instructors regardless their perceptions. TIPP provides a rich database of problems and instructors are free to choose the problems they want to use depending on the shift in thinking they want their students to achieve. The fact that one instructor perceives a retrieval problem as an analysis problem only means that they will start from different reference levels (in most of the cases justified by the interactions with their own students), but they are free to follow the direction in TIPP that is most suitable for their students.

\section{CONCLUSIONS}

Our framework seeks to group physics problems according to the cognitive processes that are needed to solve them. The Taxonomy of Introductory Physics Problems that we created has the following characteristics:

- It has a sufficient number of levels, sublevels, categories, and subcategories to include all existing physics problems within its range of applicability (introductory physics courses).

- It is based on a taxonomy of educational objectives.

- It targets the knowledge identified by PER as relevant for physics problem solving.

- It involves cognitive processes identified by PER as relevant to physics problem solving.

- It allows for both a quick, superficial usage (more suitable for instructors defining their learning objectives and their curriculum) and an in-depth analysis (more suitable for PER experimental and theoretical purposes).

- It allows future extension to metacognitive aspects, responsible for monitoring, examining, and evaluating the thought processes during problem-solving activities.

- It is suitable for any kind of instructional methodology.

We assert that our taxonomy is a theoretical construct with various practical applications. It is generally accepted that educators should, for a particular course, articulate not just general topics, but also objectives that specify the content as well as the procedures associated with that content. Using a taxonomy such as TIPP as a guideline leads to straightforward selection of problems and design of educational objectives that articulate both the specific area of information and the associated mental procedures. Given a certain background for students and the overall goals of the course, an instructor can decide to what level of thinking complexity the course should be taken. At George Washington University, we used this approach to reform our algebra-based physics course [62]. The reform improved students' problem-solving abilities and their attitudes about science.

The standard curricula found in most universities and colleges involve three types of courses: conceptual physics courses for nonscience majors with minimal or no algebra (regarded as the "easiest" course), algebrabased introductory courses for life science and premed majors (with "medium" difficulty), and calculus-based courses for engineering and physical science majors (the "hardest" course). We propose that such imprecise terms should be replaced with clear references to the levels of information, mental procedures, and cognitive processing that will be developed in the course.

After several decades of work leading to a vast amount of new curricular material based on PER studies, textbook publishers are seeking to add value to their present books by providing additional resources without overwhelming the instructor. Much of the new research-based instructional material is classified according to physics topics but not according to the thinking it entails. TIPP could allow textbook authors and developers to replace the vague "easy-medium-hard" distinction for end-of-chapter problems with a more rigorous notation that can be related to the degree of complexity of the information, mental procedures, and cognition required to solve a particular problem. Also, the importance of problem formulation has been pointed out in the literature [63] and TIPP can be used to explain how the cognitive complexity of a problem changes by altering its formulation.

So far, there are a few instruments under development to assess student physics problem-solving abilities or cognitive growth in some areas targeted by TIPP [64-66]. It is now generally accepted that new assessment 
tools should be based on a model of cognition and learning or on a description of how people represent knowledge and develop competence in a subject domain. TIPP is ideally suited to aid the development of such assessments since it is based on a model of behavior (the one inherited from NTEO) and it is designed to address both the existing physics problem-solving models and the already elucidated cognitive processes involved in physics problem solving.

Future work will seek to further validate our taxonomy based on students' performance on different kinds of problems, on the discussions that the problems trigger, and on correlations between students' scores on the problems and their scores on conceptual understanding assessments, attitudes assessments, and exams. Moreover, we want to expand the taxonomy to include metacognitive aspects of student thinking, the role of intuition, attitudes, and dispositions, and student epistemological beliefs. These aspects have been recognized as important in physics problem solving [28-30], and TIPP could be an ideal basis for research in that area.

Another important aspect that is not thoroughly detailed in this paper relates to the personal and dynamic character of student thinking. As we continue to develop TIPP, we will focus on understanding how TIPP can address the dynamic blending of the cognitive processes that take place in students' minds as they solve physics problems.

\section{SUMMARY}

While much of the new PER material is well organized according to physics topics, the attempt to classify physics problems and questions according to the cognitive processes that they involve is still in its infancy. Our research aims to find answers to the following questions:

- Can physics problems be categorized according to cognitive processes and knowledge domains?

- Is there any relationship between physics problems, knowledge domains, and cognitive processes?
- Are there relevant cognitive processes that are not activated by the existing physics problems?

We showed in this paper that physics problems can be categorized according to a set of basic cognitive processes and knowledge. We presented in Sec. IV a physics problem database that gives explanations and examples of problems that involve certain cognitive processes and knowledge. This database provides an answer to the last question, "Are there relevant cognitive processes that are not activated by the existing physics problems?" We identified certain missing types of problems (e.g., classification problems or generalizing problems).

In this paper, we also explained the algorithm that we have developed to relate physics problems to the cognitive processes and knowledge that they involve. This algorithm and our classes of problems have been discussed with other physics instructors and a validation of the taxonomy has been achieved. We asked some of these instructors to classify physics problems based on our algorithm, and acceptable agreement between their classifications has been reached. This suggests that TIPP is reliable.

This taxonomy not only establishes a relationship between physics problems, cognitive processes, and knowledge, but even more importantly, establishes a connection to relevant findings from expert-novice research and PER. As we showed in Tables IV and V, one can establish a direct correspondence between the cognitive processes used in TIPP and the ones that have to be practiced during physics instruction according to Beatty et al. [5] and the ones that take place during physics problem solving according to Tuminaro and Redish [20].

\section{ACKNOWLEDGMENTS}

We thank Nawal Benmouna, Eugenia Etkina, Tom Foster, Kathy Harper, Pat Heller, Paula Heron, Alan Van Heuvelen, David Maloney, Joe Redish, Vazgen Shekoyan, Gay Stewart, and Aaron Warren for fruitful discussions regarding this material.
[1] W. J. Gerace and I. D. Beatty, Teaching vs. Learning: Changing perspectives on problem solving in physics education, Proceedings of the 9th Common Conference of the Cyprus Physics Association and Greek Physics Association, Nicosia, Cyprus, 2005 [arXiv:physics/ 0508131].

[2] L. Hsu, E. Brewe, T. M. Foster, and K. A. Harper, Resource letter RPS-1: Research in problem solving, Am. J. Phys. 72, 1147 (2004).

[3] D. P. Maloney, Research on problem solving, in Handbook of Research on Science Teaching and Learning, edited by D. L. Gabel (Simon \& Schuster, New York, 1994).
[4] E.F. Redish, The implications of cognitive studies for teaching physics, Am. J. Phys. 62, 796 (1994).

[5] I. D. Beatty, W. J. L. Gerace, and R. J. Dufresne, Designing effective questions for classroom response system teaching, Am. J. Phys. 74, 31 (2006).

[6] L. McDermott, P. Shaffer and University of Washington Physics Education Group, Tutorials in Introductory Physics (Prentice-Hall, Englewood Cliffs, NJ, 2002).

[7] A. Van Heuvelen and E. Etkina, The Physics Active Learning Guide (Addison-Wesley, San Francisco, CA, 2006). 
[8] C. J. Hieggelke, D. P. Maloney, S. E. Kanim, and T. L. O'Kuma, E\&M TIPERs: Electricity \& Magnetism Tasks inspired by Physics Education Research (Prentice-Hall, Englewood Cliffs, NJ, 2006).

[9] P. Heller and M. Hollabaugh, Teaching problem solving through cooperative grouping. Part 2: Designing problems and structuring groups, Am. J. Phys. 60, 637 (1992).

[10] R.E. Mayer and M.C. Wittrock, Problem solving, in Handbook of Educational Psychology, edited by H. Alexander and R. Winnie (Wiley, New York, 2006), 2nd ed.

[11] A. Gupta, D. Hammer, and E.F. Redish, The case for dynamic models of learners' ontologies in physics, J. Learn. Sci. 19, 285 (2010).

[12] T. J. Bing, and E. F. Redish, Analyzing problem solving using math in physics: Epistemological framing via warrants, Phys. Rev. ST Phys. Educ. Res. 5, 020108 (2009).

[13] L. D. Conlin, A. Gupta, R. E. Scherr, and D. Hammer, The dynamics of students' behaviors and reasoning during collaborative physics tutorial sessions, in Proceedings of the 2007 Physics Education Research Conference, Greensboro, NC (AIP, New York, 2007).

[14] M. C. Lovett, Problem solving, in Memory and Cognitive Processes, Stevens' Handbook of Experimental Psychology Vol. 2, edited by D. Medlin (Wiley, New York, 2002), 3rd ed.

[15] A. D. Hauenstein, A Conceptual Framework for Educational Objectives: A Holistic Approach to Traditional Taxonomies (University Press of America, Landham, MD, 1998).

[16] E.F. Redish, R.E. Scherr, and J. Tuminaro, Reverseengineering a solution of a "simple" physics problem: Why learning physics it is harder than it looks, Phys. Teach. 44, 293 (2006).

[17] R. W. Campbell, A conceptual analysis of introductory physics textbooks, M.S. thesis, University of Arkansas, 2008.

[18] K. A. Harper, R. J. Freuler, and J. T. Demel, Cultivating problem solving skills via a new problem categorization scheme, in Proceedings of the 2006 Physics Education Research Conference, Syracuse, NY (AIP, New York, 2006).

[19] B. H. Ross, Cognitive science: Problem solving and learning for physics education, in Proceedings of the 2007 Physics Education Research Conference, Greensboro, $N C$ (Ref. [13]).

[20] J. Tuminaro and E.F. Redish, Elements of a cognitive model of physics problem solving: Epistemic games, Phys. Rev. ST Phys. Educ. Res. 3, 020101 (2007).

[21] B.S. Bloom, Taxonomy of Educational Objectives, Handbook I: The Cognitive Domain (David McKay, New York, 1956).

[22] L. W. Anderson, D. R. Krathwohl, P. W. Airasian, K. A. Cruikshank, R. E. Mayer, P. R. Pintrich, J. Raths, and M. C. Wittrock, A Taxonomy for Learning, Teaching and Assessing. A Revision of Bloom's Taxonomy of Educational Objectives (Addison-Wesley, New York, 2001).

[23] T.M. Haladyna, Writing Test Items to Evaluate Higher Order Thinking (Allyn \& Bacon, Boston, MA, 1997).
[24] L.S. Hannah and J. U. Michaelis, A Comprehensive Framework for Instructional Objectives: A Guide to Systematic Planning and Evaluation (Addison-Wesley, Reading, MA, 1977).

[25] J. Biggs and K. Collis, Evaluating the Quality of Learning: The SOLO taxonomy (Academic, New York, 1982).

[26] R. J. Marzano and J.S. Kendall, The New Taxonomy of Educational Objectives (Corwin Press, Thousand Oaks, CA, 2007), 2nd ed.

[27] I. Halloun and D. Hestenes, Interpreting VASS dimensions and profiles for physics students, Sci. Educ. 7, 553 (1998).

[28] W. K. Adams, K. K. Perkins, N. S. Podolefsky, M. Dubson, N.D. Finkelstein, and C.E. Weiman, A new instrument for measuring student beliefs about physics and learning physics: The Colorado Learning Attitudes about Science Survey, Phys. Rev. ST Phys. Educ. Res. 2, 010101 (2006).

[29] E. F. Redish, R. N. Steinberg, and J. M. Saul, Student expectations in introductory physics, Am. J. Phys. 66, 212 (1998).

[30] A. Elby, Helping physics students learn how to learn, Am. J. Phys., 69, S54 (2001); see also A. Elby, http://www2.physics.umd.edu/ elby/EBAPS/home.htm (extracted Feb. 2010).

[31] A. Giambattista, B. Richardson, and R.C. Richardson, College Physics (McGraw-Hill, New York, 2007).

[32] University of Maryland tutorials, http://umdperg .pbworks.com/Tutorials-from-the-UMd-PERG (extracted Feb. 2010).

[33] A. Hobson, Physics Concepts and Connections (PrenticeHall, Englewood Cliffs, NJ, 2006), 3rd ed.

[34] P. P. Urone, College Physics (Brooks-Cole, Pacific Grove, CA, 1998).

[35] J. Mestre, Probing adults' conceptual understanding and transfer of learning via problem posing, J. Appl. Dev. Psychol. 23, 9 (2002). In this paper, problem posing activity is used as a research tool.

[36] A. Van Heuvelen and D. Maloney, Playing physics jeopardy, Am. J. Phys. 67, 252 (1999).

[37] R. A. Serway and J. W. Jewett, Physics for Scientists and Engineers (Thompson, Pacific Grove, CA, 2008), 7th ed.

[38] Multiple representation tasks have been developed by Rutgers University Physics Education Research Group. They are available at http://paer.rutgers.edu/ scientificAbilities/Downloads/FormAssessTasks/MultRep .pdf (extracted Feb. 2010).

[39] T.L. O'Kuma, D. P. Maloney, and C. J. Hieggelke, Ranking Task Exercises in Physics (Prentice-Hall, Englewood Cliffs, NJ, 2000).

[40] D. P. Maloney, Ranking tasks: A new type of test item, J. Coll. Sci. Teach. 16, 510 (1987); see also D. P. Maloney and A. W. Friedel, Ranking tasks revisited, J. Coll. Sci. Teach. 25, 501 (1996).

[41] J.D. Marx, K. Cummings, and T. French, Problem classification tasks, American Association of Physics Teachers Meeting, San Diego, CA, 2001 (unpublished).

[42] M. T. H. Chi, P. J. Feltovici, and R. Glaser, Categorization and representation of physics problems by experts and novices, Cogn. Sci. 5, 121 (1981). 
[43] A. Van Heuvelen, Active Learning Problem Sheets (ALPS kits) (Hayden McNeil Publishing, Inc., Plymouth, MI, 1995) (out of print)

[44] A. Van Heuvelen, Overview, case study physics, Am. J. Phys. 59, 898 (1991).

[45] K.A. Harper, Z.D. Hite, R. J. Freuler, and J.T. Demel, Student categorization of problems-An extension, in Proceedings of the 2007 Physics Education Research Conference, Greensboro, NC (Ref. [13]). In this paper, problems that contain excess or insufficient information have been used as a research tool.

[46] L. Weinstein and J. A. Adam, Guesstimation (Princeton University Press, Princeton, NJ, 2008).

[47] A. R. Warren, Evaluation strategies as means for learning physics, Ph.D. thesis, Rutgers University, 2006, http:// faculty.pnc.edu/arwarren/Thesis/Thesis.htm.

[48] P.C. Peters, Even honors students have conceptual difficulties with physics, Am. J. Phys. 50, 501 (1982).

[49] Evaluation tasks have been developed by Rutgers University Physics Education Research Group, http://paer.rutgers .edu/scientificAbilities/Downloads/FormAssessTasks/Eval .pdf (extracted Feb. 2010).

[50] R. Catrambone, Generalizing solution procedures learned from examples, J. Exp. Psychol. Learn. Mem. Cogn. 22, 1020 (1996).

[51] R.D. Knight, Physics for Scientists and Engineers. A Strategic Approach (Pearson Education, Sacramento, CA, 2004).

[52] A. Van Heuvelen, Experiment problems for mechanics, Phys. Teach. 33, 276 (1999).

[53] A. Van Heuvelen, L. D. Allen, and P. Mihas, Experiment problems for electricity and magnetism, Phys. Teach. 37, 482 (1999).

[54] N. Lerman, Open-ended problem instruction in general physics, Am. J. Phys. 32, 927 (1964).
[55] P. D'Alessandris, SPIRALPhysics Active Learning, http:// web.monroecc.edu/manila/webfiles/spiral/SpiralArticle .pdf (extracted Feb. 2010).

[56] V. Shekoyan, Using multiple-possibility problems in introductory physics courses, Ph.D. thesis, Rutgers University, 2009.

[57] L. L. Morris and C. T. Fitz-Gibbon, How to Measure Program Implementation (Sage, Newbury Park, CA, 1978).

[58] W. Wiersma and S. G. Jurs, Educational Measurement and Testing (Allyn \& Bacon, Boston, MA, 1990).

[59] J. Cohen, A coefficient of agreement for nominal scales, Educ. Psychol. Meas. 20, 37 (1960).

[60] P. G. Hewitt, Conceptual Physics (Addison-Wesley, San Francisco, 2006), 10th ed.

[61] J.S. Walker, Physics (Pearson Education, New York, 2004), 2nd ed.

[62] R. E. Teodorescu, Cognitive development in introductory physics: A research-based approach to curriculum reform, Ph.D. thesis, The George Washington University, 2009.

[63] J. Slisko, How can formulation of physics problems and exercises aid students in thinking about their results?, Latin-Am. J. Phys. Educ. 2, 138 (2008).

[64] W. Adams and C. Weiman, Problem solving skill evaluation instrument, in Proceedings of the 2006 Physics Education Research Conference, Syracuse, NY (Ref. [18]).

[65] J. Docktor, Robust assessment instrument for student problem solving, on Proceedings of the 2009 NARST Annual Meeting, Garden Grove, CA, 2009 (National Association for Research in Science Teaching, Garden Grove, CA, 2009).

[66] K. Cummings and J.D. Marx, Robust beta-test data on an assessment of textbook problem solving ability: An argument for right/wrong grading, in Proceedings of the 2010 Physics Education Research Conference, Portland, OR (AIP, New York, 2010). 